\title{
STENTED LICH-GREGOIR URETERONEOCYSTOSTOMY IN RENAL TRANSPLANTATION: AN EXPERIENCE AT BANGABANDHU SHEIKH MUJIB MEDICAL UNIVERSITY IN BANGLADESH
}

\author{
ATM A ULLAH ${ }^{1}, M_{\text {HOSSAIN }}^{1}, M^{2}$ N HOODA ${ }^{2}$, MS ISLAM $^{3}$, MM HAQUE $^{4}$, AKM K ALAM $^{5}$, AKM A ISLAM $^{5}$ \\ SAM G KIBRIA
}

\begin{abstract}
Ureteral reimplantation is one of the important components of reconstruction of urinary tract in renal transplantation. There are various techniques of ureteral reimplantation, of which Extravesical Lich-Gregoir is the ideal technique for renal transplantation. Extravesical ureteroneocystostomy to reestablish urinary tract continuity in renal transplantation has been examined through a study of 140 kidney transplants leading to the finding that stented anastomosis was associated with a lower urologic complication rate. We now report the urologic complication rate in our case series in which stented Lich-Gregoir anastomosis was routinely utilized.

Methods. The records of 140 consecutive renal transplants were reviewed. Minimum follow-up time was 3 months. The standard anastomosis was a Lich-Gregoir with a 5-6 Fr cm D-J stent. Monitored urologic complications included postoperative vesicoureteral leak or ureteral necrosis, obstruction or stricture, or clinically significant hematuria.
\end{abstract}

Results. One urologic complication were noted-one leak and no other complication. There were no stentrelated complications requiring reoperation. There were no cases in which the urologic complication led to graft loss or patient death.

Conclusions. The urologic complication rate in this case series is less to the five previously published randomized trials, as well as our previous study. These results support the routine use of a ureteral stent.

\section{Introduction}

Ureteral reimplantation is one of the important components of reconstruction of urinary tract in renal transplantation. Various techniques of ureteral reimplantation have been described for different indication. Indication of reimplantation are numerous and varied. Five techniques were used by Aboutaieb and colleagues like Leduc-Camey, Leadbetter-Politano, Direct, Manchette, Lich-Gregoir as transvesical and extravesical procedure and conclude Lich-Gregoir is the ideal technique for renal transplantation (Aboutaieb et al-1996) ${ }^{1}$. Urinary tract reconstruction is usually by antireflux ureteroneocystostomy, of which there are various techniques for ureteroneocystostomy in renal transplantation (Leadbetter-Politano-1958, Mac kinnon et al-1968, Konack et al-1975, Texter et al-1976, Barry 1983) ${ }^{2}$. Intravesical and extravesical ureteroneocystostomy are the two principle approaches for reestablishing urinary tract continuity in renal transplantation ${ }^{3}$. Extravesical ureteroneocystostomy has become the standard for reestablishment of urinary tract continuity in renal transplantation given its technical ease and low complication rate. Evaluation of this technique has covered some 50 years of surgical progress.

R.Khauli have previously reviewed 49 published reports in which a Lich-Gregoir anastomosis was utilized, performing a meta-analysis to compare stented versus nonstented anastomoses. The stented Lich-Gregoir anastomosis was found to show a highly significant reduction in complication rate re $^{2-3}$. Multiple case series have been published in the past 8 (eight) years which establish the urologic complication rates of stented extravesical reconstructions between $0 \%$ and $4.6 \% 4$ 13. Five randomized controlled trials have been reported with stented ureteroneocystostomy complication rates ranging between $0 \%$ and $3.5 \% 3-4,13-17$. Other recent reports, using a nonstented, Extravesical technique, show more variability with complication rates ranging between $2.8 \%$ and $21.4 \%{ }^{3-4,13-15}$. In our previous study of comparison between stented and nonstented ureteroneocystostomy in renal transplantation, found that there was no complication in stented cases except few infections ${ }^{2}$. This paper reports the complication rate of routine stented Lich-Gregoir ureteroneocystostomy among 140 consecutive renal transplants over 6 and $1 /$ 2 years.

\section{Methods}

The records of 140 consecutive renal transplants were reviewed, covering the 6 and $1 / 2$ year period between 
January 2003 and June 2009. Routinely collected values included both laboratory and clinical data from the time of the transplant. Minimum follow-up time for this analysis was 3 months. All transplants were performed at a single hospital by different surgeons; the database review was completed by a third, independent physician. Identified urologic complications included postoperative vesicoureteral leak or ureteral necrosis, obstruction or stricture, or clinically significant hematuria. The incidence of vesicoureteral reflux and urinary tract infection was not quantitated for this report. Immunosuppression included induction with prednisolone and maintenance therapy with prednisone, tacrolimus or cyclosporine, and mycophenolate mofetil. Rejection episodes were treated with pulse dose steroids.

All transplants were performed using a standard retroperitoneal approach with pelvic placement of the kidney and vascular anastomoses to the external iliac artery and vein. A Lich-Gregoir extravesical ureteroneocystostomy was constructed over a ureteral stent. An antireflux tunnel was routinely constructed using the bladder wall, thereby covering the ureteroneocystostomy. The stent as a D-J stent which ranged in size from 4 to $6 \mathrm{Fr}$ and in length from 16 to 26 $\mathrm{cm}$. An extravesical external drainage device was routinely used. Drain was removed 4-7th postoperative day except one which was removed at 15 days. The urinary bladder catheter was routinely removed on postoperative day $7-10$. Stent removal by routine cystoscopy after 6 weeks as outpatient under local anesthesia.

\section{Results}

Among the 140 recipients, 109 were men. All are live related donor kidneys. Recipient ages ranged from 17 to 53 years, with a mean age of 30.98 years. There were no death and or graft rejection within 30 days of transplantation. All transplants were single kidney only with no multivisceral procedures. There was one urologic complication $(0.71 \%)$ : one patient experienced leak. There were no stent-related complications. Several patients with persistent postoperative urinary infections had the stent removed sooner than the routine 6 weeks. There were no cases in which a urologic complication led directly to graft loss or patient death. Among the patient with urinary complication with leakage required conservative management with 15 days catheterization. Patient stayed in hospital for 30 day as our protocol. No patient need overstay in hospital. The costs associated with patient time, pain, and anxieties are impossible to quantify.

\section{Discussion}

The extravesical ureteroneocystostomy is a simple, easy to reestablishing urinary tract continuity in renal transplantation. This approach is associated with a low complication rate and is simple to teach and to learn.

Thus, most centers have adopted this technique. Many surgeons have added the step of placing a ureteral stent across this anastomosis with recent published urologic complication rates ranging from $0.0 \%$ to $4.6 \%$ with a stent in place. A meta-analysis, which includes data from over 14,000 kidney transplants from 5 randomized controlled trials and 44 case series, shows the stented anastomosis to have a significantly lower complication rate when compared to a nonstented anastomosis. We now present the results of 140 renal transplants completed over 6 and $1 / 2$ years in which a ureteral stent was routinely used in conjunction with an extravesical anastomosis. We found a $0.71 \%$ urologic complication rate with no stent-related graft loss or significant patient morbidity. The physiologic benefit of the ureteral stent may derive from postoperative ureteral decompression. The stent allows for continued urinary flow during the period of postoperative edema in which the anastomosis may be compromised by high intraluminal pressure ${ }^{3}$. The inherent stiffness of the stent may keep the ureter aligned, thereby minimizing kinking.

Proposed drawbacks to stent use include the increased risk of postoperative urinary infection, dislodgement of the stent resulting in injury or obstruction, ureteral erosion, and the need for a posttransplant invasive procedure for stent removal. In our population, we did not document any occurrences of stent dislodgement or ureteral erosion. There were patients who required stent removal for persistent urinary infection, although the exact number was not documented. There were no instance of graft loss related to stent use. Because we did not have any instance of stent-related obstructive or migration complications, these potential associated costs were not included in our overall cost-effectiveness analysis.

This case series demonstrates that routine stenting of the Lich-Gregoir ureteroneocystostomy is clinically feasible and is associated with a low urologic complication rate. Khauli and Ayvazian ${ }^{13}$ reported a series of 300 consecutive stented renal allografts using a modified extravesical ureteroneocystostomy reporting 
no ureteral or bladder leaks, with $0.7 \%$ of patients developing a delayed stenosis. Five randomized, controlled trials since 1995 have directly compared stented and nonstented anastomoses. Among these studies, the stented grafts consistently showed a lower urologic complication rate, which ranged between $0.0 \%$ and $3.5 \%$. This compares to urologic complication rates between $6.6 \%$ and $13.3 \%$ for nonstented anastomoses within these same five randomized trials.

The present report of nearly 400 transplants in which a stented anastomosis was utilized is similarly successful, supporting the routine use of a ureteral stent for extravesical ureteroneocystostomy. The costs associated with stent use are relatively minimal compared to the overall costs associated with management of leak in kidney transplant. In one calculation, the cost of preventing each leak is approximately $\$ 15,000^{13}$. Human and socieal costs for these complications are impossible to quantify. Some ureteral strictures and leaks can be managed with minimally invasive techniques such as antegrade or percutaneous stenting, but other complications require reoperation, can lead to graft loss, and may be associated with patient death.

\section{Conclusion}

Based on the available evidence, we suggest routine use of stent in all renal transplants for prevention of urologic complications.

\section{References}

1. Aboutaieb R, Rabii R, El Mrini M, Benjelloun S. Ureteral reimplantation. Ann Urol. 1996; 30 (5): 240-3.

2. ATM Aman Ullah, MS Islam, C M Hossain, S Islam, $S$ Jahan et al: Comparative study of stented and nonstented ureteroneocystostomy in renal transplantation. Bangladesh Journal of Urology, July 2006, vol 29, no 2, 41-49.

3. Mangus RS and Haag BW. Stented versus nonstented extravesical ureteroneocystostomy in renal transplantation: A Metaanalysis. Am J Tranplant 2004;4:1-8.

4. Mangus RS, Haag BW and Carter CB. Stented Lich-Gregoir ureteroneocystostomy: Case series report and cost-effectiveness analysis. Tranplant proc 2004; 36: 2959-2961.

5. Anderson EE, Glenn JF, Seiglen HF et al, Urological complication in renal transplantation $\mathrm{J}$ Urol, 1972;107:185-192.

6. Barry JM. Renal Transplantation, Campbell's Urology. $8^{\text {th }}$ edition, Saunders 2002; 345-376.
7. Barry JM. Unstented extravesical ureteroneocystostomy in kidney transplantation. J Urol 1983; 129: 918-919.

8. Benoit G, Blanchet P, Eschwege P, Alexandre L, Bensadoun $\mathrm{H}$, Charpentier $\mathrm{B}$. Insertion of a double $\mathrm{J}$ ureteral stent for the prevention of urological complications in renal transplantation: A prospective randomized study. J Urol 1996;156:81-84.

9. Breton PN, Malone MJ. Renal transplantation. Tanagho EA and MC Aninch JW Smith's General Urology. Sixteenth edition, MacGraw-Hill, 2004, 614-625.

10. Briones MG, Burgos Revilla FJ, fascaul Santos J, Marcen Letosa R, Pozo Mengual B, Arambarri Segura M, Fernandez Fernandez E, Ecudero Barrilero, Ortuno Mirete J. Comparative study of ureteral anastomosis with or without double-J catheterization in renal transplantation. Actas Urol Esp 2001; 25(7): 499-503.

11. Caparros J, Regalado RI, Sanchez-Martin F, Villavicencio h. A simplified technique for ureteroneocystostomy in renal transplantation. world J Urol. 1996; 14 (4); 236-8.

12. David L,Nicol, Kenny P'Ng, Hardie, Daryl R Wall and lan $\mathrm{R}$ Hardie. Rouine use of indwelling ureteral stents in renal transplantation. J Urol 1993;150:1375-1379.

13. Khauli RB, Ayvazian PJ. Modified extravesical ureteroneocystostomy and routine ureteral stenting in renal transplantation: experience in 300 consecutive cases. Transplant Proc 2001; 33: 2665-2666.

14. Khauli RB. Modified extravesical ureteroneocystostomy and routine ureteral stenting in cadaveric renal transplantation. Transplant Proc 1991; 23: 2627-2628.

15. Khauli R. Modified extravesical ureteral reimplantation and routine stenting in kidney transplantation. Transplan.2002 Sep; 15(8): 411-4.

16. Mehta SN, Kennedy JA, Loughridge WGG, Douglas JF, Donaldson RA, McGeown MG. Urological complications in 119 consecutive renal transplants. Br J Urol 1979; 51:184-187.

17. Mundy AR, Podesta ML,Bewick M, Rudge CJ and Ellin FG; Urological complications of 1000 renal transplants.Brit, J Urol, 1981; 53:397.

Authors:

1. Assistant Proressor of Urology, BSMMU

2. Assistant Professor of Urology, NIKDU

3. Assistant Professor of Urology, Rangpur Medical College

4. Assistant Professor of Urology, Chittagong Medical College

5. Professor of Urology, BSMMU, Dhaka 